\title{
A Prediction Method of Historical Timber Buildings' Vibrations Induced by Traffic Loads and Its Validation
}

\author{
Yunshi Zhang, Nan Zhang, Yanmei Cao, and He Xia \\ School of Civil Engineering, Beijing Jiaotong University, Beijing 100044, China \\ Correspondence should be addressed to Nan Zhang; nzhang@bjtu.edu.cn
}

Received 17 September 2016; Revised 7 December 2016; Accepted 13 December 2016; Published 7 March 2017

Academic Editor: Vadim V. Silberschmidt

Copyright (c) 2017 Yunshi Zhang et al. This is an open access article distributed under the Creative Commons Attribution License, which permits unrestricted use, distribution, and reproduction in any medium, provided the original work is properly cited.

\begin{abstract}
A prediction method in the frequency domain is proposed for predicting the vibrations of historical timber building induced by traffic loads. The modal parameters of a structure are identified using a double-confirmation analysis method based on the autospectrum. Then, the vibration responses of the building are calculated using a limited number of measurement records by inputting the calculated vibration information for the foundation of the updated building model. The proposed method is used to predict the vibrations of the Buddhist sutra depositary at Yangzhou Zhunti Temple. Comparing the results shows that the vibration responses of a structure under traffic loads can be effectively predicted in the relevant frequency bands.
\end{abstract}

\section{Introduction}

Wooden structures played a vital role in Chinese architectural history. Wooden architecture is a treasure that combines structural form and architectural art, and ancient Chinese wooden architecture made excellent contributions to promoting the development of historic timber buildings. However, over time, the reliability and bearing performance of these wooden structures are constantly decreasing. The attenuation of the structural performance of historical timber building is rapidly increasing with increased people loads and surrounding traffic loads. Consequently, the vibration prediction and evaluation of historical timber buildings subjected to ambient traffic loads are necessary so that vibration isolation measures can be applied to limit the damage to these buildings and to extend their service life.

Researchers have conducted many studies to analyze the vibrations of historic buildings [1-22]. The dynamic characteristics of structures have been measured using field tests based on the ambient vibration exactions $[1,2,5]$; the identified modal parameters were then used to update the finite element (FE) model of the target structure [8, 13-15, 21], which was in turn used to develop the prediction methods. Breccolotti et al. [10] established a methodology for predicting the vibration levels induced by railway traffic. Crispino and D’Apuzzo [17] measured road traffic-induced vibrations in a heritage building in Naples and compared the results to a prediction model. Ding et al. [19] predicted the free field vibrations induced by metro trains using the coupled periodic finite element-boundary element (FE-BE) method. Chebli et al. [20] proposed a method for calculating the response of periodic structures induced by moving loads. Some other work also has been done: Cagnan [3] assessed the seismic performance of an old cathedral using ambient vibration test results. Ceroni et al. [4] compared the eigenfrequencies and vibration modes of a structure measured from test results and calculated by an FE model that included the soil-structure interaction. Foti et al. [6] presented the process of updating a 3D finite element model of a building based on field tests. Rainieri et al. [7] proposed a valuable tool for the indirect noninvasive structural assessment of historical structures using the combination of ambient vibration tests and model refinement. Cacciola and Tombari [9] made a vibrating barrier to reduce the vibrations of structures by exploiting the structure-soil mechanism. Giulio et al. [11] presented the main modal parameters of a church by evaluating the test data. Sevim et al. [12] assessed the nonlinear seismic performance of a restored historical masonry arch bridge using ambient vibrations. El-Attar et al. [14] proposed passive control techniques to control structural vibrations. Marchisio 


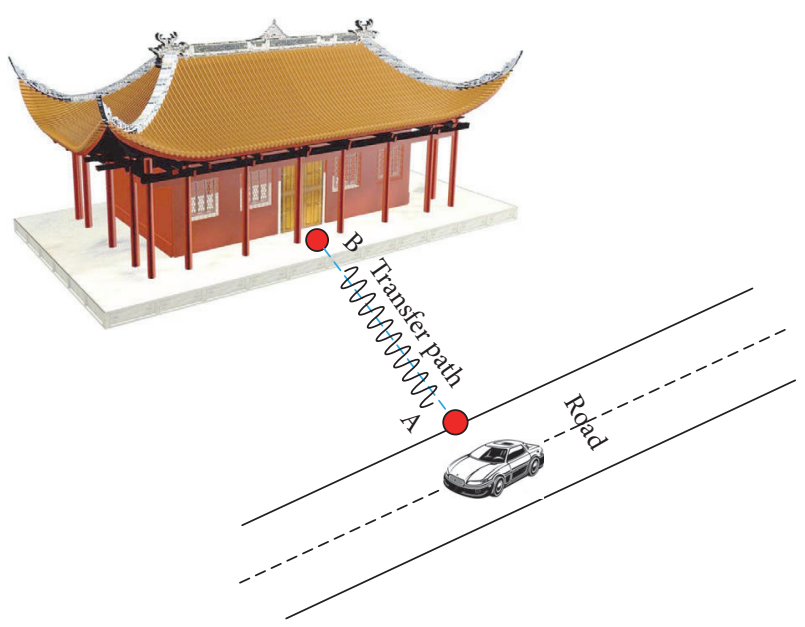

FIGURE 1: Layout of the measurement points.

et al. [16] studied the dynamic behavior of the Leaning Tower of Pisa under different exactions.

The prediction model for structural vibrations can be divided into several parts, such as the vibration sources, the transfer path of vibration waves in the free field, and the interaction between the soil and the structural foundation; therefore, simulating these parts in one prediction model is difficult. In addition, due to the particularities of ancient architecture, these buildings cannot be tested too often, so if an effective vibration prediction method can be proposed, the harm to the ancient architecture brought by the field test and larger traffic loads will be reduced.

In this paper, a new prediction method in the frequency domain is proposed and validated through a field test. In this method, the transfer ratio in the frequency domain is combined with an FE model to reduce the scale of the prediction model and the computing time. Using the proposed method, the vibration responses of the structure can be obtained effectively without detailed field test. A field vibration test was conducted at the Yangzhou Zhunti Temple, and the updated FE model of the sutra depository was established using the identified modal parameters. Then, the vibration responses of the structure induced by larger traffic loads were predicted using the transfer method in the frequency domain. The aim of this article is to provide an effective prediction method for the structural vibrations and to provide a reference for researchers in the field of structural vibration prediction under traffic loads.

\section{Prediction Method}

The prediction model is developed as follows: (1) the vibrations at position $\mathrm{A}$ near the road and at position $\mathrm{B}$ at the structural foundation induced by the same vehicle are measured, as indicated in Figure 1; (2) the transfer ratio for each single frequency is calculated and the time history of each single frequency at position B is obtained; (3) the modal parameters of the structure are identified by analyzing the

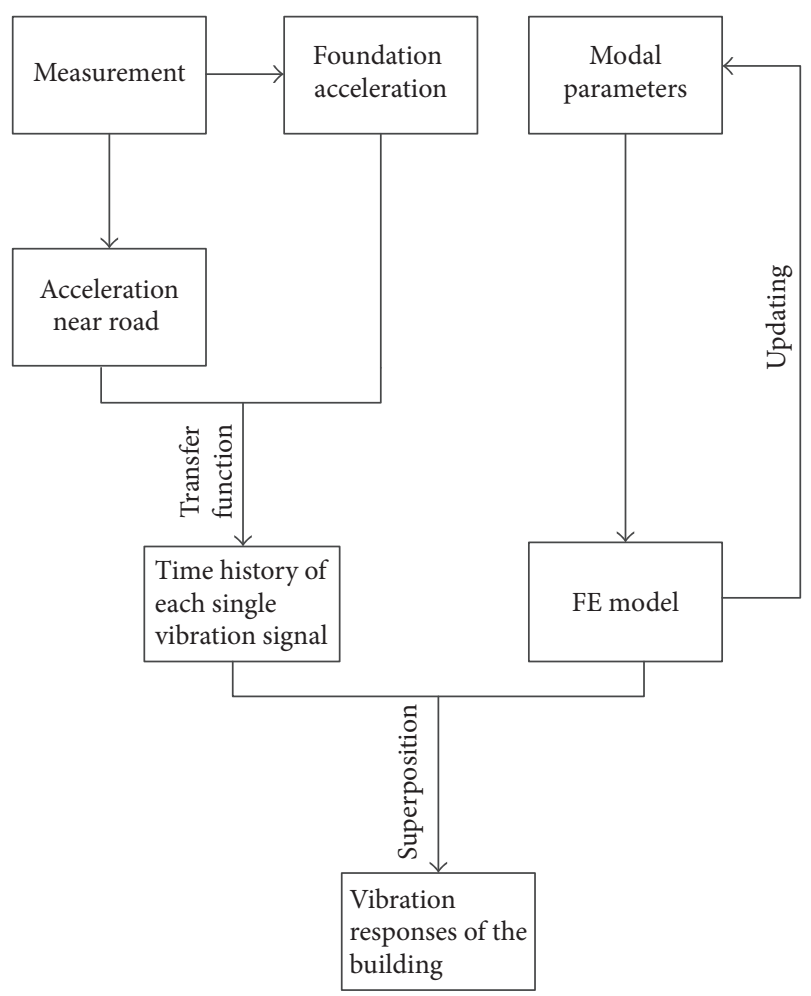

Figure 2: Sketch of the prediction model.

field test data; (4) the FE model of the structure is updated and used to calculate the structural vibration responses induced by each single vibration signal, and (5) the vibrations of the building can be calculated, as shown in Figure 2 .

2.1. Transfer Function in the Frequency Domain. If the force acting on a multiple degrees-of-freedom (MDOF) system is defined as a harmonic load, then the dynamic equation of the system can be written as

$$
\mathbf{M} \ddot{\mathbf{X}}+\mathbf{C X}+\mathbf{K X}=\mathbf{P} \sin \theta t
$$

where $\mathbf{M}, \mathbf{C}$, and $\mathbf{K}$ are the mass, damping, and stiffness matrices of the system, respectively, $\ddot{\mathbf{X}}, \dot{\mathbf{X}}$, and $\mathbf{X}$ are the acceleration, velocity, and displacement vectors, respectively, and $\mathbf{P}$ is the force vector of the system.

The mode is processed orthogonally:

$$
M_{n} \ddot{Y}_{n}+C_{n} \dot{Y}_{n}+K_{n} Y_{n}=\phi_{n}^{T} \mathbf{P} \sin \theta t=P_{n} \sin \theta t
$$

where $M_{n}, C_{n}$, and $K_{n}$ are the mass, damping, and stiffness of the $n$th degree-of-freedom (DOF), respectively, $\ddot{Y}, \dot{Y}$, and $Y$ are the acceleration, velocity, and displacement vectors, respectively, and $P_{n} \sin \theta t$ is the force of the $n$th DOF.

According to structural dynamics, the solution of (1) can be expressed as

$$
Y_{n}=\rho_{n} \sin \left(\theta t-\alpha_{n}\right)
$$


where $\rho_{n}=\left(P_{n} / K_{n}\right)\left(1 / \sqrt{\left(1-\theta / \omega_{n}\right)^{2}+\left(2 \xi_{n} \theta / \omega_{n}\right)^{2}}\right), \alpha_{n}=$ $\tan ^{-1}\left(2 \xi_{n}\left(\theta / \omega_{n}\right) /\left(1-\theta^{2} / \omega_{n}^{2}\right)\right), \omega_{n}=\sqrt{K_{n} / M_{n}}$

$$
\begin{aligned}
\mathbf{X} & =\sum_{i=1}^{N} \phi_{i}^{T} Y_{i}=\sum_{i=1}^{N}\left[\phi_{i}^{T} \rho_{n} \sin \left(\theta t-\alpha_{n}\right)\right] \\
& =\mathbf{S}_{1} \sin \left(\theta t-\alpha_{1}\right)+\cdots+\mathbf{S}_{n} \sin \left(\theta t-\alpha_{n}\right) \\
& =\left\{\begin{array}{c}
r_{1} \sin \left(\theta t-\beta_{1}\right) \\
r_{2} \sin \left(\theta t-\beta_{2}\right) \\
\vdots \\
r_{n} \sin \left(\theta t-\beta_{n}\right)
\end{array}\right\} .
\end{aligned}
$$

When $t_{1}=t+2 \pi / \theta$,

$$
\mathbf{X}^{\prime}=\left\{\begin{array}{c}
r_{1} \sin \left(\theta t+\theta \frac{2 \pi}{\theta}-\beta_{1}\right) \\
r_{2} \sin \left(\theta t+\theta \frac{2 \pi}{\theta}-\beta_{2}\right) \\
\vdots \\
r_{n} \sin \left(\theta t+\theta \frac{2 \pi}{\theta}-\beta_{n}\right)
\end{array}\right\}=\mathbf{X} .
$$

Thus, the steady-state vibration response of each DOF has a single frequency, and the vibration frequency is the same as the excitation frequency when an MDOF system is subjected to a single frequency excitation.

When the load in (1) changes, the input loads increase linearly with the slope $\lambda$; then the dynamic equation of the system can be written as

$$
\mathbf{M} \ddot{\mathbf{X}}+\mathbf{C} \dot{\mathbf{X}}+\mathbf{K X}=\lambda \mathbf{P} \sin \theta t=\mathbf{Q} \sin \theta t,
$$

where $\mathbf{M}, \mathbf{C}$, and $\mathbf{K}$ are the mass, damping, and stiffness matrices of the system, respectively, $\ddot{\mathbf{X}}, \dot{\mathbf{X}}$, and $\mathbf{X}$ are the acceleration, velocity, and displacement vectors, respectively, and $\mathbf{Q}$ is the force vector of the system.

The mode is processed orthogonally:

$$
M_{n} \ddot{Y}_{n}+C_{n} \dot{Y}_{n}+K_{n} Y_{n}=\phi_{n}^{T} \mathbf{Q} \sin \theta t=\lambda P_{n} \sin \theta t .
$$

The solution of (6) is

$$
\begin{aligned}
Y_{n} & =\lambda \rho_{n} \sin \left(\theta t-\alpha_{n}\right) \\
\mathbf{X} & =\sum_{i=1}^{N} \phi_{i}^{T} Y_{i}=\sum_{i=1}^{N}\left[\phi_{i}^{T} \lambda \rho_{n} \sin \left(\theta t-\alpha_{n}\right)\right] \\
& =\lambda \mathbf{S}_{1} \sin \left(\theta t-\alpha_{1}\right)+\cdots+\lambda \mathbf{S}_{n} \sin \left(\theta t-\alpha_{n}\right) \\
& =\left\{\begin{array}{c}
\lambda r_{1} \sin \left(\theta t-\beta_{1}\right) \\
\lambda r_{2} \sin \left(\theta t-\beta_{2}\right) \\
\vdots \\
\lambda r_{n} \sin \left(\theta t-\beta_{n}\right)
\end{array}\right\} .
\end{aligned}
$$

Thus, the amplitude ratio between different DOFs is constant when the input loads increase linearly with the slope $\lambda$.

According to classical structural dynamics, the vibration signal at any time can be written as by a series of simple harmonic waves:

$$
A(t)=\sum_{k=1}^{n} A_{k}\left(\omega_{k}, t, \varphi_{k}\right)
$$

When the vibrations and the transfer function between two points are obtained, the vibration of the prediction point can be calculated as follows:

(1) Process the acceleration histories $x_{1}(t)$ at point $A$ and $y_{1}(t)$ at point $B$ that are induced by the same vehicle using the following Fourier transform

$$
\begin{aligned}
& X_{1}(\omega)=\int_{-\infty}^{+\infty} x_{1}(t) e^{-j \omega t} d t \\
& Y_{1}(\omega)=\int_{-\infty}^{+\infty} y_{1}(t) e^{-j \omega t} d t
\end{aligned}
$$

(2) Calculate the transfer function $H(\omega)$ between point A and point $B$ :

$$
H(\omega)=\frac{X_{1}(\omega)}{Y_{1}(\omega)} .
$$

With another acceleration history $x_{2}(t)$, the processed result of $x_{2}(t)$ is $X_{2}(\omega)$, and the Fourier transform processed result $Y_{2}(\omega)$ of the acceleration history $y_{2}(t)$ at point $\mathrm{B}$ can be calculated.

(3) Calculate $y_{2}(t)$ using following function:

$$
y_{2}(t)=\frac{1}{2 \pi} \int_{-\infty}^{\infty} Y_{2}(\omega) e^{j \omega t} d \omega .
$$

2.2. Modal Parameters Identification. Structural vibration signals under traffic loads have the following problems: (1) the input cannot be accurately known; (2) the vibration signals are comprehensively influenced by many vehicle loads, making it impossible to obtain a free attenuation signal of the structure under a single vehicle load; (3) the vibration signals are greatly affected by environmental vibrations. Based on the above constraints, the traditional methods for the modal parameters identification of structure in the time domain or in the frequency domain are not applicable for this test. Yuan et al. [21] proposed a new method for identifying the modal parameters by comprehensively analyzing the autocorrelation function, frequency response function, transfer function, and cross-correlation function of the vibration signals.

The frequency response function $H(\omega)$ is defined as

$$
|H(\omega)|^{2}=\frac{G_{y y}(\omega)}{G_{f f}(\omega)},
$$

where $G_{y y}(\omega)$ and $G_{f f}(\omega)$ are the autopower spectra of the structural responses and the excitation force, respectively. 
The environmental vibration excitation is assumed to be a white noise excitation; namely, $G_{f f}(\omega)=c, c$ is constant. Then the natural frequencies of the structure can be obtained using the autopower spectra of the structural vibration signals. The peaks corresponding to the frequency induced by the white noise excitation are the structural natural frequencies. However, the measured structural vibration signals are also affected by pedestrian walking and electrical signals, often resulting in false peaks in the frequency spectra. Therefore, the cross-power spectral density (PSD) function is used between different measurement points to improve the analysis accuracy. If the peaks of the auto-PSD and the cross-PSD appear at the same frequency, then the frequency corresponding to each peak can be considered one of the natural frequencies of the structure.

The frequency response function is defined as the frequency response ratio of the measurement point and the reference point under environmental excitation. The vibration response at the reference point is defined as the input signal, and the responses at the measurement points are the output signals under the influence of the environmental excitation. Then, the coefficients of the vibration modes can be defined as

$$
\begin{array}{r}
\Phi=\frac{\left|H_{m}(\omega)\right|}{\left|H_{n}(\omega)\right|} \\
H(\omega)=\frac{S_{x y}(\omega)}{S_{x x}(\omega)},
\end{array}
$$

where $\Phi$ is the coefficient of the vibration mode, $H(\omega)$ is the transfer function, $S_{x x}(\omega)$ is the auto-PSD function, and $S_{x y}(\omega)$ is the cross-PSD function. The sign of $\Phi$ is determined by the phase relationships of the cross-PSD between different measurement points: the sign is positive for the same phase and it is negative for different phase [21].

2.3. Building Vibrations under Multisupport Excitations. The dynamic equation of a discrete building model is

$$
\mathbf{M} \ddot{\mathbf{s}}+\mathrm{C} \dot{\mathbf{s}}+\mathbf{K s}=\mathbf{P}
$$

where $\mathbf{M}, \mathbf{C}$, and $\mathbf{K}$ are the mass, damping, and stiffness matrices of the building, respectively, $\ddot{\mathbf{s}}, \dot{\mathbf{s}}$, and $\mathbf{s}$ are the acceleration, velocity, and displacement vectors, respectively, and $\mathbf{P}$ is the force vector of the building FE model.

Here, the large-mass method is used to excite the forced movement, and multilumped masses are attached to the excited positions of the building foundation. The DOF along the $j$-direction of the excited positions is released and the force $P_{j}$ is applied to the lumped-mass in the same direction,

$$
P_{j}=M_{0} \ddot{s}_{0}
$$

where $M_{0}$ is the virtual lumped-mass and $\ddot{s}_{0}$ is the input acceleration. Then, the dynamic equation of the lumped-mass can be rewritten as

$$
\begin{aligned}
& {\left[\begin{array}{ccccc}
m_{11} & \cdots & m_{1 j} & \cdots & m_{1 n} \\
\vdots & \ddots & \vdots & \ddots & \\
m_{j 1} & \cdots & M_{0} & \cdots & m_{j n} \\
\vdots & \ddots & \vdots & \ddots & \\
m_{n 1} & \cdots & m_{n j} & \cdots & m_{n n}
\end{array}\right]\left(\begin{array}{c}
\ddot{s}_{1} \\
\vdots \\
\ddot{s}_{j} \\
\vdots \\
\ddot{s}_{n}
\end{array}\right)} \\
& +\left[\begin{array}{ccccc}
c_{11} & \cdots & c_{1 j} & \cdots & c_{1 n} \\
\vdots & \ddots & \vdots & \ddots & \\
c_{j 1} & \cdots & c_{j j} & \cdots & c_{j n} \\
\vdots & \ddots & \vdots & \ddots & \\
c_{n 1} & \cdots & c_{n j} & \cdots & c_{n n}
\end{array}\right]\left(\begin{array}{c}
\ddot{s}_{1} \\
\vdots \\
\ddot{s}_{j} \\
\vdots \\
\ddot{s}_{n}
\end{array}\right) \\
& +\left[\begin{array}{ccccc}
k_{11} & \cdots & k_{1 j} & \cdots & k_{1 n} \\
\vdots & \ddots & \vdots & \ddots & \\
k_{j 1} & \cdots & k_{j j} & \cdots & k_{j n} \\
\vdots & \ddots & \vdots & \ddots & \\
k_{n 1} & \cdots & k_{n j} & \cdots & k_{n n}
\end{array}\right]\left(\begin{array}{c}
s_{1} \\
\vdots \\
s_{j} \\
\vdots \\
s_{n}
\end{array}\right) \\
& =\left(\begin{array}{c}
p_{1} \\
\vdots \\
M_{o} \ddot{s}_{0} \\
\vdots \\
p_{n}
\end{array}\right) .
\end{aligned}
$$

The $j$ th component of (17) is expanded as

$$
\begin{aligned}
m_{j 1} \ddot{s}_{1} & +\cdots+M_{0} \ddot{s}_{j}+\cdots+m_{j n} \ddot{s}_{n}+c_{j 1} \dot{s}_{1}+\cdots+c_{j j} \dot{s}_{j} \\
& +\cdots+c_{j n} \dot{s}_{n}+k_{j 1} s_{1}+\cdots+k_{j j} s_{j}+\cdots+k_{j n} s_{n} \\
= & M_{0} \ddot{s}_{0} .
\end{aligned}
$$

The large-mass $M_{0}$ is much larger than all the remaining mass $m$ on the left side of (18); thus, $\ddot{s}_{j} \approx \ddot{s}_{0}$. The vibration responses of the remaining input points of the foundation can also be calculated using the above method.

In the large-mass method, the parameter of $M_{0}$ is usually defined as $10^{5}$ times the total structure mass in this paper.

\section{Test of the Zhunti Temple}

3.1. General Information. The Yangzhou Zhunti Temple was built during the late Ming dynasty. The distance between Zhunti Temple and Yanfu east road is only $14 \mathrm{~m}$, and large vehicle flows are common on this road during morning 


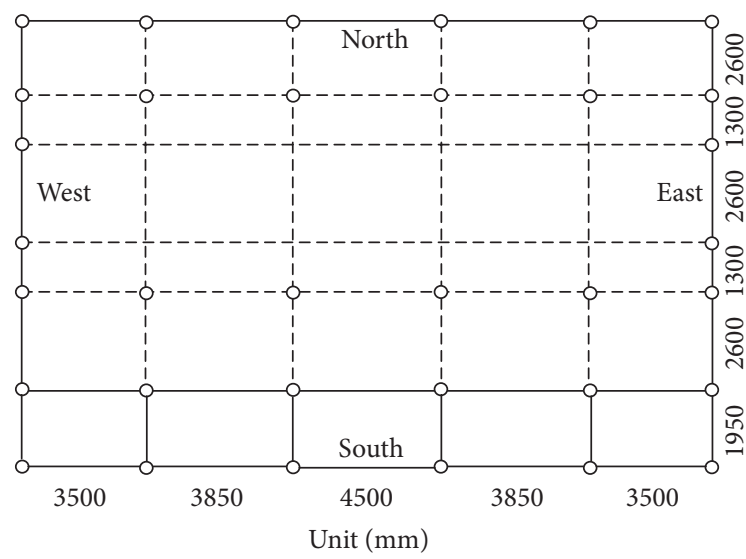

Figure 3: Top view of the depository of Buddhist sutra.

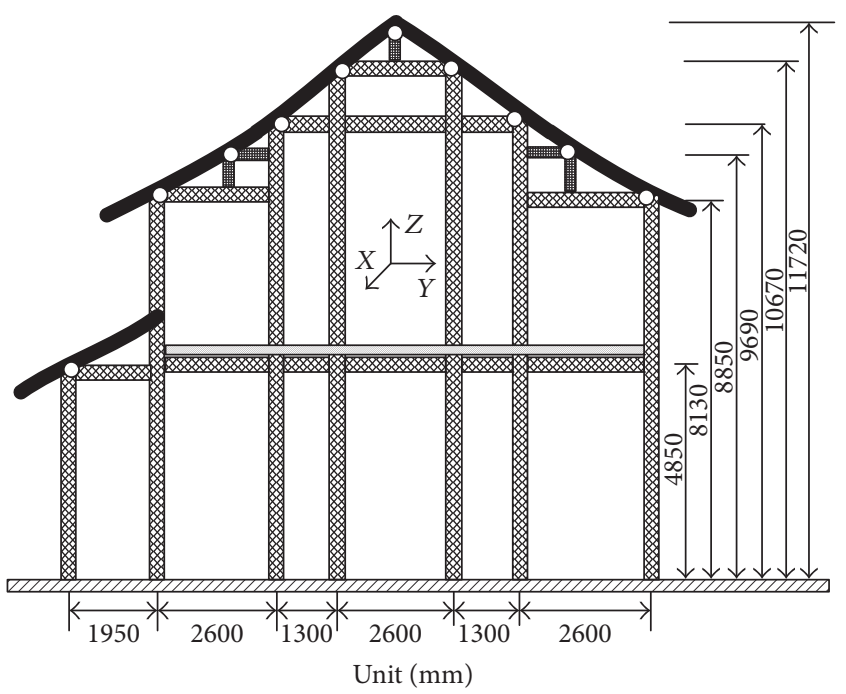

FIgURE 4: Side view of the of Buddhist sutra depository.

and evening rush hours. Therefore, the vibrations of sutra depository induced by the traffic loads are considerable. The sutra depository is made of wood and includes 2 floors and 34 columns. The columns are connected with each other by Fang and beam, and the connections between the beams and columns are mortise-tenon connections. The gables at eastern and western sides of the building are constructed of brick, and the columns are located outside of the gables. The top and side view of the sutra depository are shown in Figures 3 and 4 , respectively.

The measurement points on the 1st floor and 2nd floor were arranged near the pillars and on top of the columns. Here, the top of the pillar is defined as the 3rd floor. The specific arrangement of the measurement points is shown in Figure 5.

Because the structural responses under the traffic loads are mainly composed of low frequency signals, 941B sensors were used to measure the ground and the structure vibrations due to the micro tremors and general structural vibration,

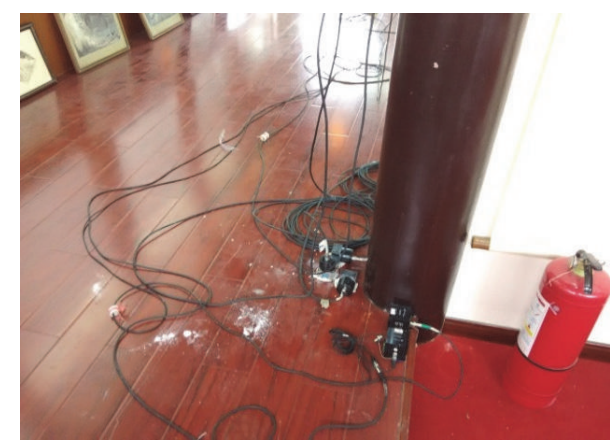

(a) On site

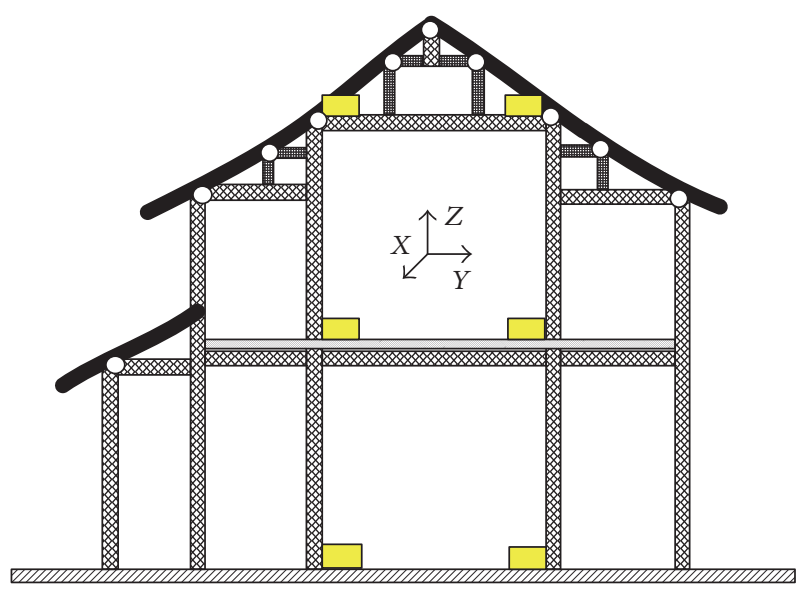

Measurement point

(b) Side view

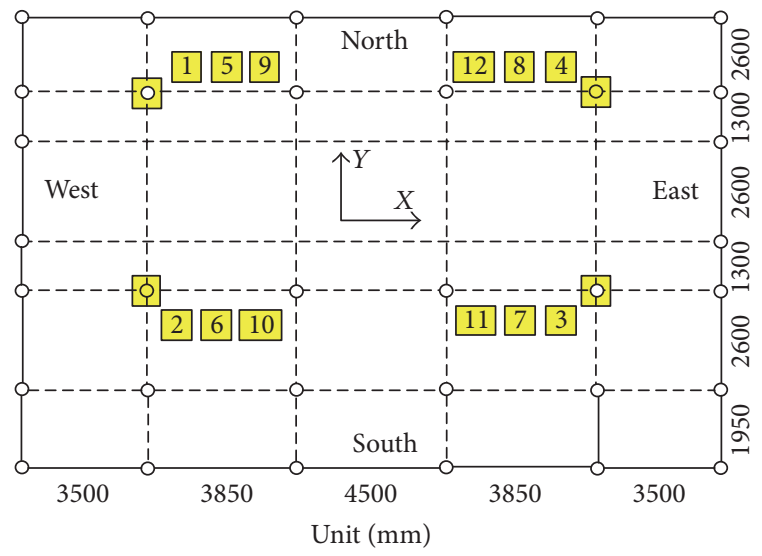

Measurement point

(c) Top view

FIGURE 5: Measurement points layout.

and the sensitivity of the accelerometer can meet the need of the required test precision. According to the traffic flow in the morning and evening, the test period was divided into 3 parts: 6:30 9:30, 17:00 20:00, and 23:00 1:00. The sampling frequency of the test was $1024 \mathrm{~Hz}$, and the sampling time of each group was $1200 \mathrm{~s}$. 


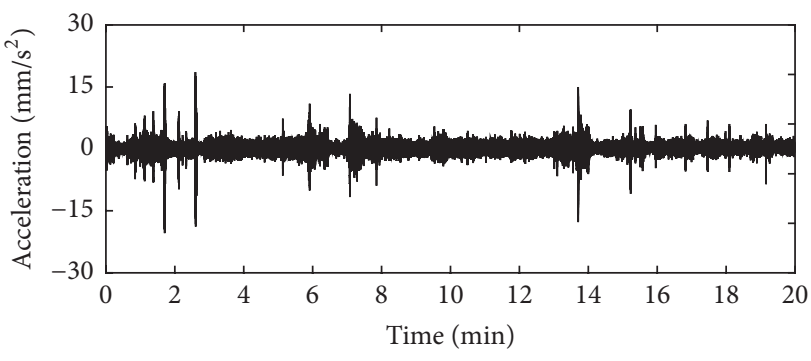

(a) $X$-direction

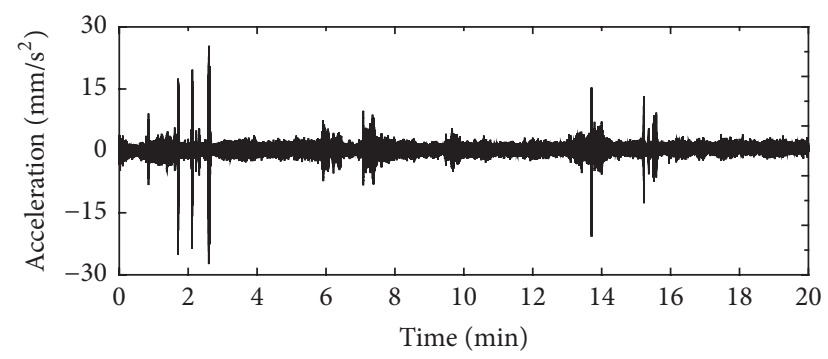

(b) $Y$-direction

FIgure 6: Acceleration histories of the 2nd floor.

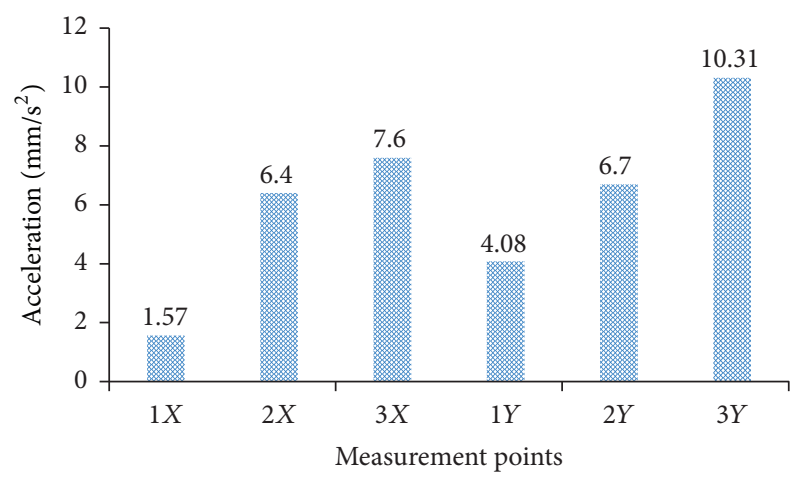

FIGURE 7: The average maximum acceleration for each floor.

3.2. Vibration in the Time Domain. According to the specification [23], the vibrations in the horizontal direction are taken as the assessment value. The horizontal acceleration histories measured on the 2nd floor are shown in Figure 6.

The test data acquired during morning and evening rush hours are used for statistical analysis. The processing method in the time domain is as follows: (1) the test data within one second are averaged to obtain a total of 1200 values; (2) to eliminate the interference of the ambient vibration, the highest $5 \%$ of the acceleration data are deemed as invalid and excluded; the maximum value of the residual data is selected as the representative acceleration value; (3) the maximum acceleration of each measurement point in each group is obtained; and (4) the average value of the representative acceleration from the measurement points on the same floor is defined as the structural vibration response, as shown in Figure 7.

Thus, the acceleration in $X$-direction and $Y$-direction increased at higher floors, and the acceleration in $Y$-direction is greater than that in the $X$-direction on the same floor. The maximum acceleration in the $X$-direction and $Y$ direction, which occurred on the third floor, was $7.6 \mathrm{~mm} / \mathrm{s}^{2}$ and $10.31 \mathrm{~mm} / \mathrm{s}^{2}$, respectively, under the traffic loads during morning and evening rush hours.

3.3. Vibration in the Frequency Domain. The vibration signals of the 2nd floor under the traffic loads during morning and evening rush hours are analyzed using spectrum analysis, and the dominant frequency bands are shown in Figure 8.
TABLE 1: The identified first 2 natural frequencies and modal factors of the structure.

\begin{tabular}{lcc}
\hline Order & 1 & 2 \\
Direction & $X$ & $Y$ \\
Natural frequencies $(\mathrm{Hz})$ & 2.84 & 3.09 \\
Modal factors & & \\
$\quad$ 1st floor & 0 & 0 \\
2nd floor & 0.72 & 0.72 \\
3rd floor & 1 & 1 \\
\hline
\end{tabular}

The dominant frequency bands of the structural vibration induced by the traffic loads during morning and evening rush hour were $10 \mathrm{~Hz} \sim 20 \mathrm{~Hz}$, and the dominant frequency bands were approximately the same in the $X$-direction and the $Y$ direction for the same measurement point.

The vibration signals are processed in the frequency domain using Fourier transform. However, only the dominant frequency bands are obtained; obtaining the transfer law of each single frequency vibration signal is difficult. Therefore, the vibration signals are processed by one-third octave processing to determine the influence of each single frequency vibration signal on the whole structural vibration, as shown in Figure 9.

The maximum vibration levels corresponding to the central frequencies in the $X$-direction is $59.3 \mathrm{~dB}$ on the 3rd floor, and the corresponding frequency is $25 \mathrm{~Hz}$; the maximum vibration levels corresponding to the central frequencies in the $Y$-direction is $56.3 \mathrm{~dB}$ on the $3 \mathrm{rd}$ floor, and the corresponding frequency is $12.5 \mathrm{~Hz}$. The vibration levels corresponding to the central frequencies in the $X$-direction and $Y$-direction increased at higher floors.

\section{Identification of the Structural Parameters}

The structural vibrations of the 2 nd and 3rd floor near the same pillar are analyzed using the autocorrelation function and cross-correlation function, as shown in Figure 10.

Only the first two natural frequencies can be obtained from the frequency spectra due to the interference from the ambient vibration. The first two natural frequencies and the normalized modal factors are shown in Table 1.

To forecast the vibration response of the structure under heavy trunks, an FE model of the Buddhist sutra depository 


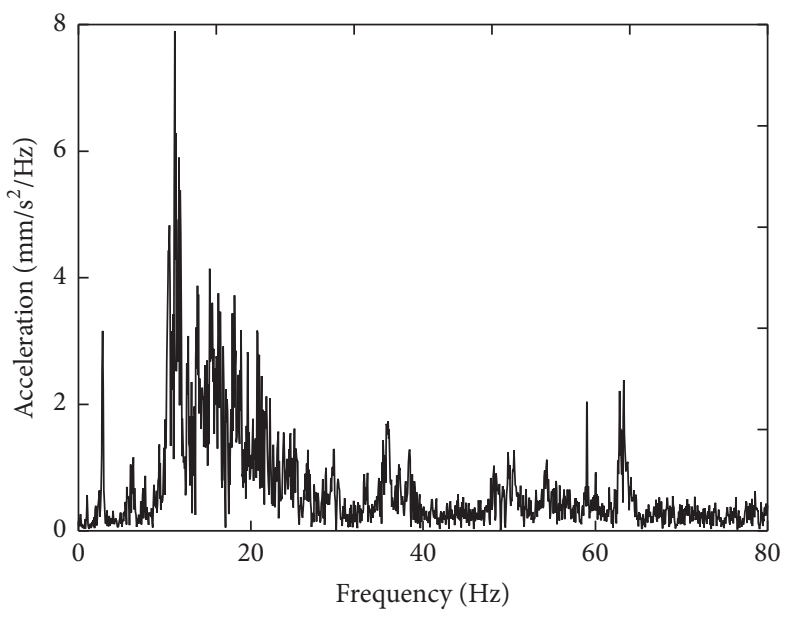

(a) $X$-direction

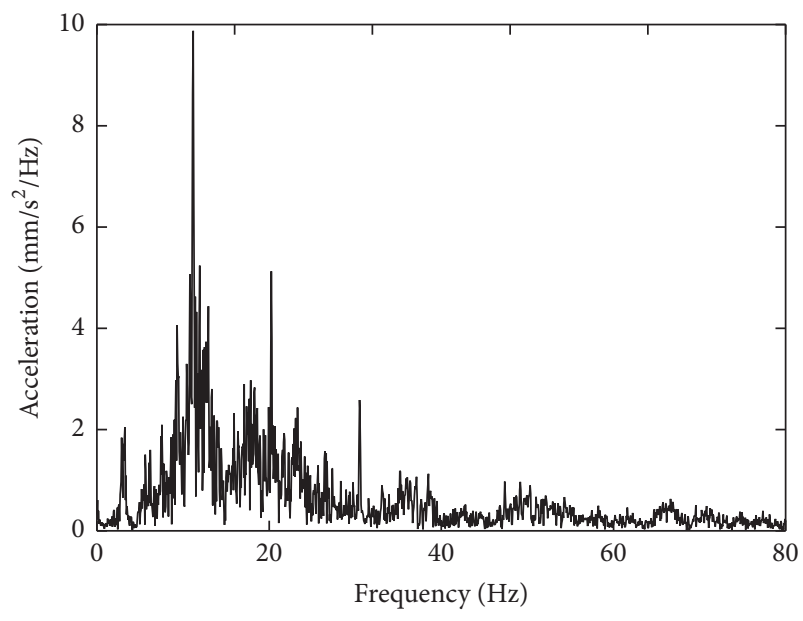

(b) $Y$-direction

FIGURE 8: Spectrum of the vibration signals of the 2nd floor.

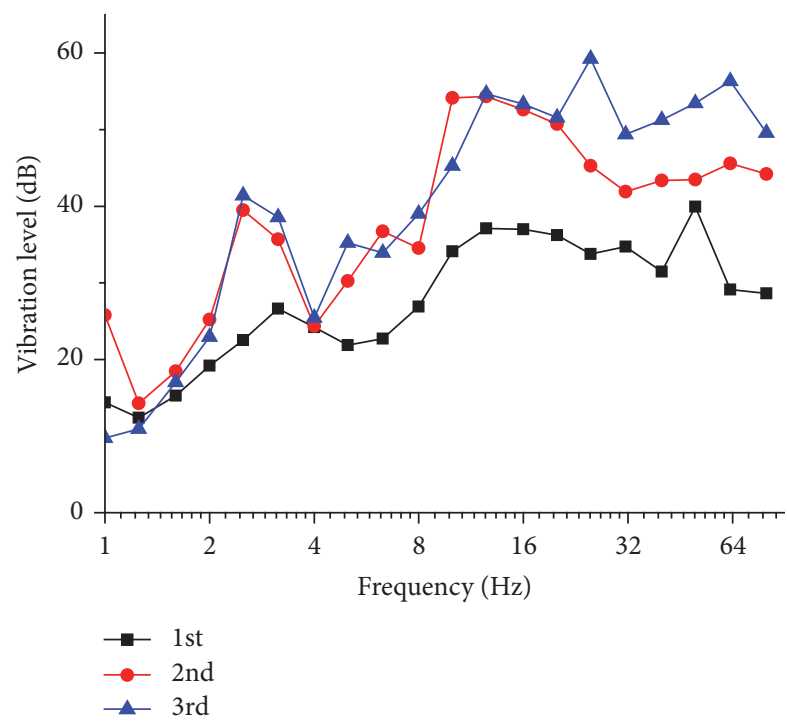

(a) $X$-direction

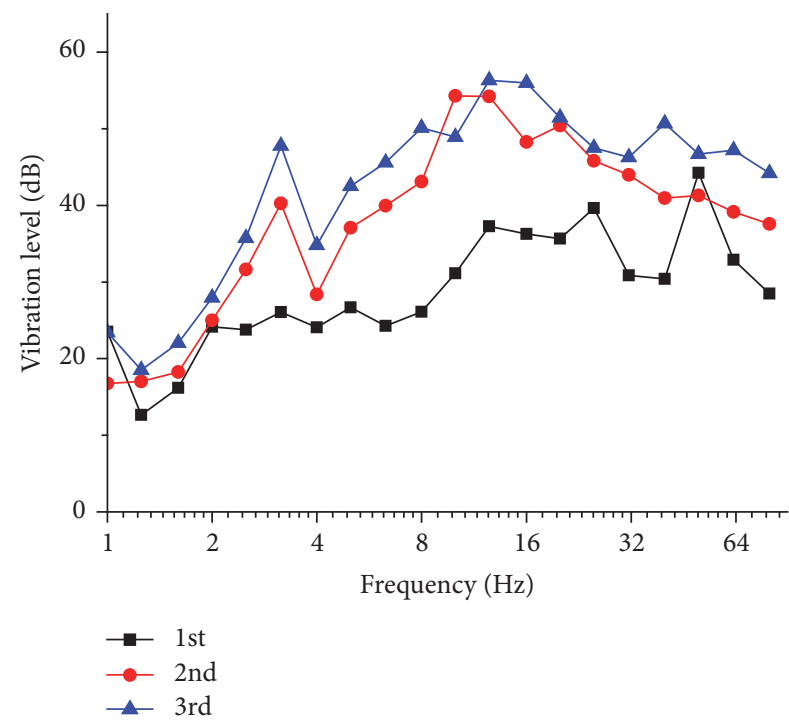

(b) $Y$-direction

FIgURE 9: One-third octave spectrum of vibration signal.

was constructed. The FE model of the structure is developed using ANSYS. BEAM188 elements are used to model the pillars, fangs, and beams of the structure, and SHELL181 elements are used to model the floors and roof of the structure. The elastic modulus and density of the wood are $1.207 e 4 \mathrm{MPa}$ and $497 \mathrm{~kg} / \mathrm{m}^{3}$, respectively. The established FE model of the structure is shown in Figure 11.

The first 2 mode shapes of the structure are shown in Figure 12.

To verify the accuracy of the established FE model, the modal parameters are calculated, and the measured and calculated first 2 natural frequencies of the structure are listed in Table 2. In addition, Figure 13 compares the measured and the calculated normalized coefficients of the structural vibration modes.
TABLE 2: The measured and calculated first 2 natural vibration frequencies of the structure.

\begin{tabular}{lccc}
\hline Order & FEM $(\mathrm{Hz})$ & Measured $(\mathrm{Hz})$ & Direction \\
\hline 1 & 2.84 & 2.84 & $X$ \\
2 & 3.13 & 3.09 & $Y$ \\
\hline
\end{tabular}

Table 2 and Figure 13 show that the relative error of the structural natural frequencies between the measured and calculated values is less than $1.2 \%$. Moreover, the relative error of the structural modal factors between the measured and calculated is less than $17.8 \%$. Therefore, the FE model can be used to predict the vibration response of the building under heavy trunks. 


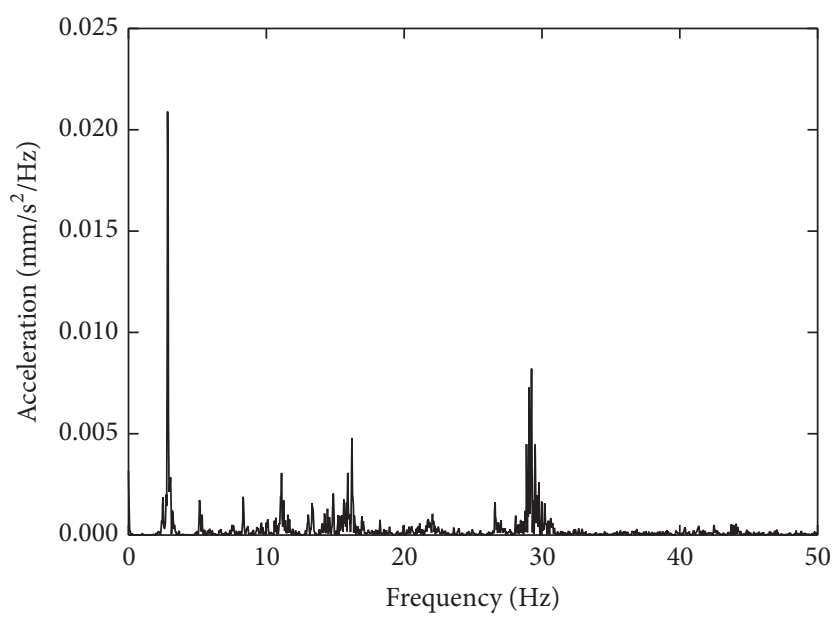

(a) Autopower spectrum in the $X$-direction

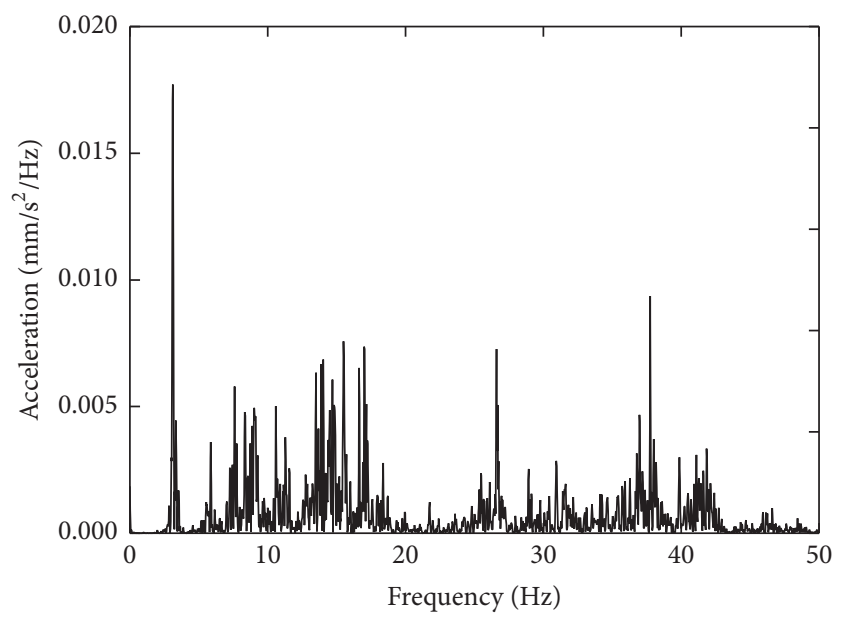

(c) Autopower spectrum in the $Y$-direction

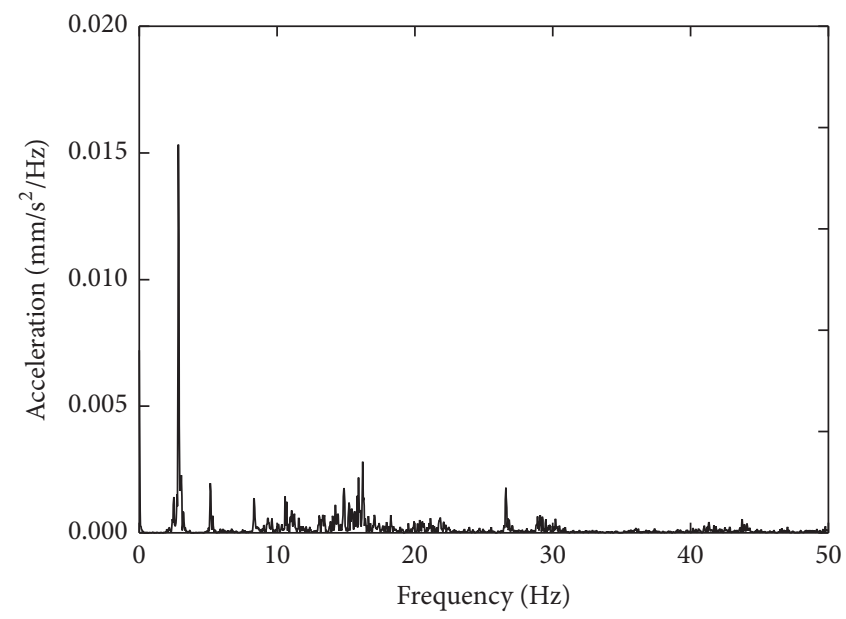

(b) Cross-power spectrum in the $X$-direction

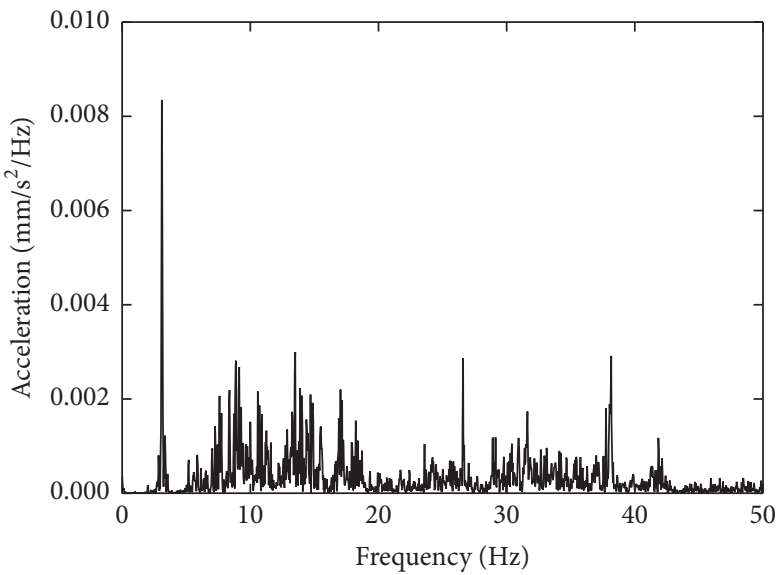

(d) Cross-power spectrum in the $Y$-direction

FIGURE 10: Autopower spectrum and cross-power spectrum for the 2nd and 3rd floor.

\section{Prediction of the Structural Vibration under Heavy Trunks}

5.1. Transfer Function. To obtain the vibrations near the resource, the accelerometers are arranged along the side of the road in front of the structure and on the first floor of the Buddhist sutra depository. The acceleration of the roadside and the structural foundation induced by the same vehicle is collected simultaneously. The arrangement of measurement points is shown in Figure 14.

The acceleration of point $\mathrm{A}$ and point $\mathrm{B}$ shown in Figure 14 induced by the same vehicle is processed. Then, the time histories of each central frequency in the onethird octave processing spectrum are obtained, as shown in Figure 15. The ratio of the maximum acceleration point $A$ to that of point B for the same single frequency is defined as the transfer ratio. Due to the limited length of this paper, only the acceleration time history for the frequency band $12.5 \mathrm{~Hz}$ is shown in Figure 15.

The acceleration induced by a typical vehicle is processed, and the acceleration time histories of each central frequency

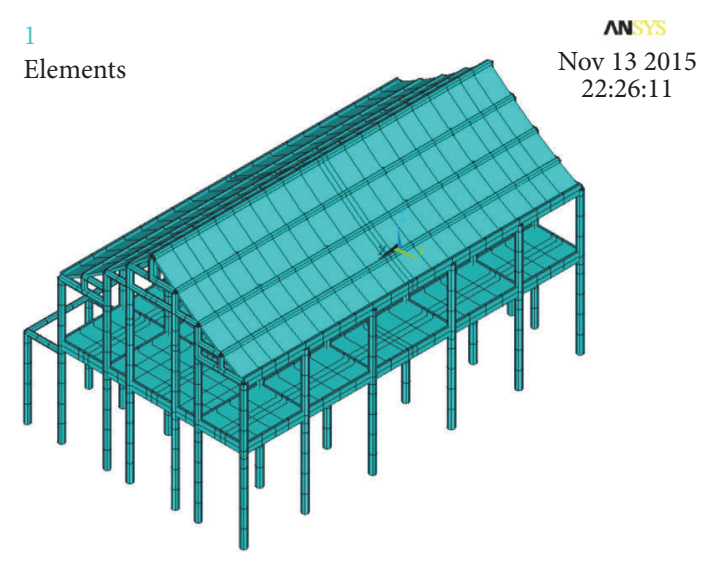

Figure 11: FE model of the depositary of Buddhist sutra.

in the one-third octave processing spectrum are obtained. The maximum acceleration values of each central frequency are shown in Figure 16. 


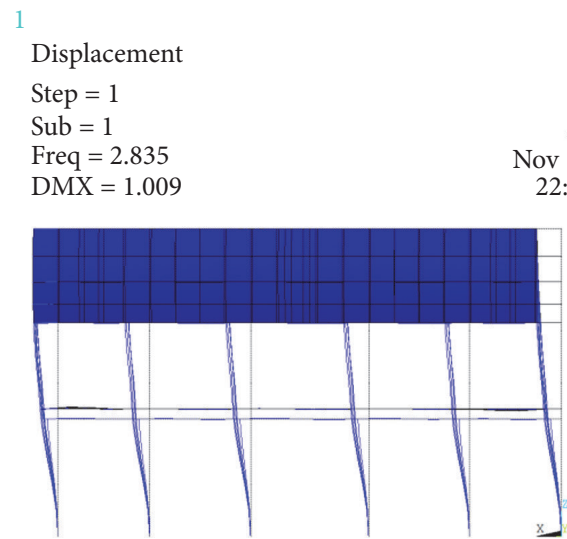

(a) 1 st

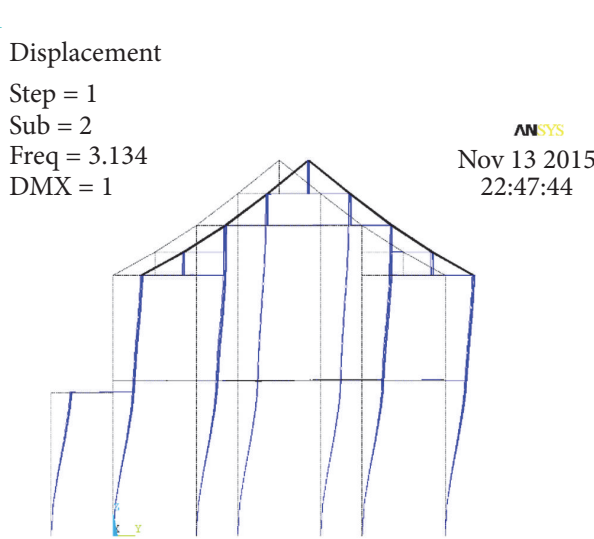

(b) 2nd

FIGURE 12: The first 2 vibration mode shapes of the structure.

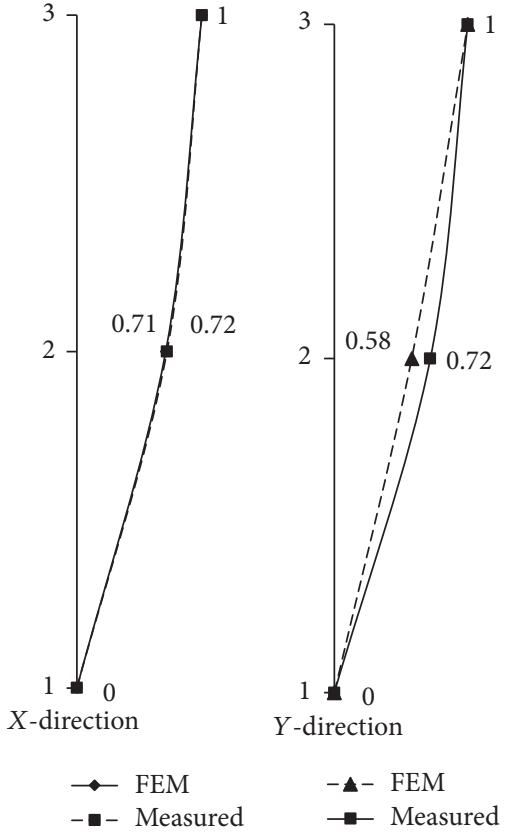

FIgURE 13: Comparison of modal factors.

The single frequency vibration signals in the dominant frequency band are the main components of the vibration signals; therefore, the vibration signals in the dominant frequency band are analyzed in this paper. The acceleration time histories of each central frequency in the dominant frequency band of $10 \mathrm{~Hz} 20 \mathrm{~Hz}$ are extracted, and finally the transfer ratio of each single frequency between point $\mathrm{A}$ and point $B$ is obtained. The transfer ratio for each single frequency between point $A$ and point $B$ may be affected by the ambient vibrations and the transfer path; therefore, multiple groups of test data are analyzed, and the rest of the data are averaged to eliminate some outliers. The transfer ratios for frequency $10 \mathrm{~Hz}, 12.5 \mathrm{~Hz}, 16 \mathrm{~Hz}$, and $20 \mathrm{~Hz}$ in the dominant frequency band $10 \sim 20 \mathrm{~Hz}$ are shown in Table 3 .

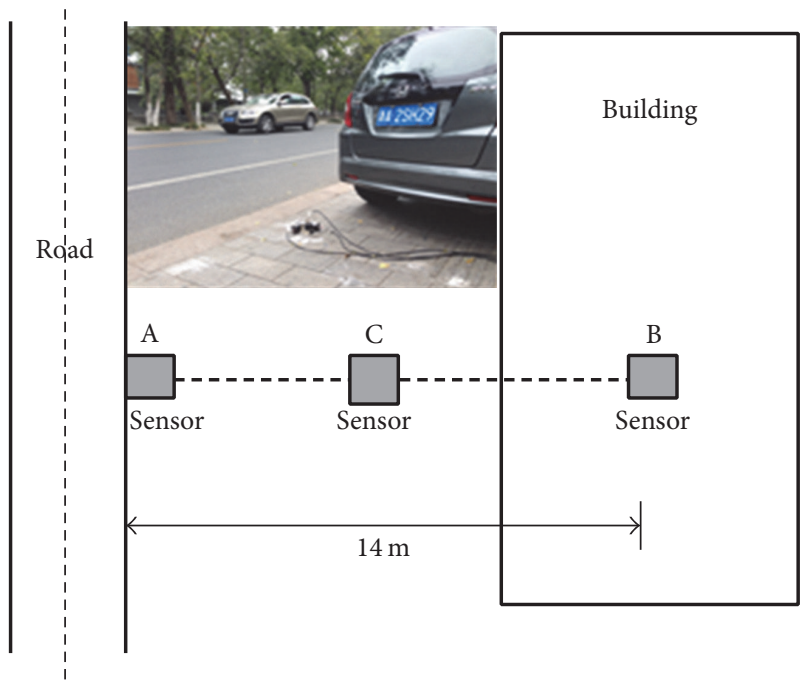

FIGURE 14: Layout of the measurement points.

TABLE 3: Transfer ratios corresponding to the central frequencies.

\begin{tabular}{lc}
\hline Central frequency $(\mathrm{Hz})$ & Transfer ratio \\
\hline 10 & 0.6 \\
12.5 & 0.45 \\
16 & 0.39 \\
20 & 0.32 \\
\hline
\end{tabular}

To verify the accuracy of the FE model and the rationality of the method proposed in this paper, the acceleration of point A induced by a typical vehicle is analyzed. In addition, the acceleration of the 2 nd floor induced by the same vehicle can be obtained using the prediction method proposed in this paper; the acceleration values at the measurement point on the 2nd floor obtained from the field test and from the prediction method are shown in Figure 17. Additionally, because the predicted point is close to point $\mathrm{A}$ and because the time that the vibration waves take to travel from point 


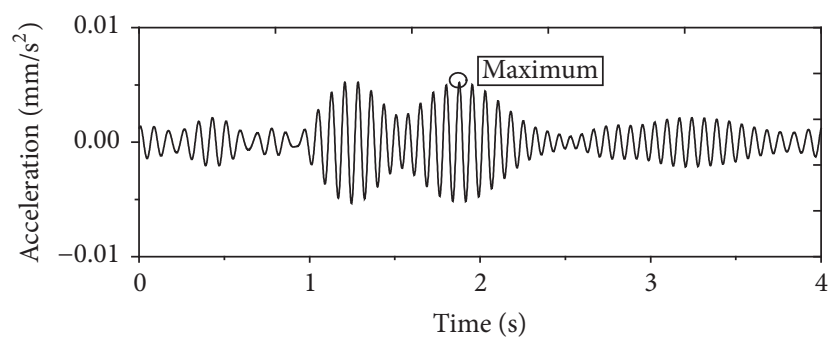

(a) Acceleration history of point $\mathrm{A}$

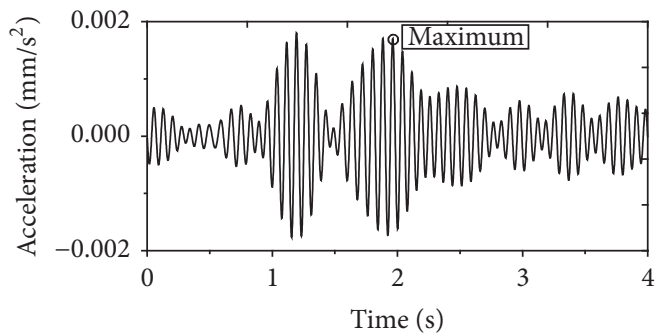

(b) Acceleration history of point $\mathrm{B}$

FIgURE 15: Acceleration histories of points A and B at $12.5 \mathrm{~Hz}$.

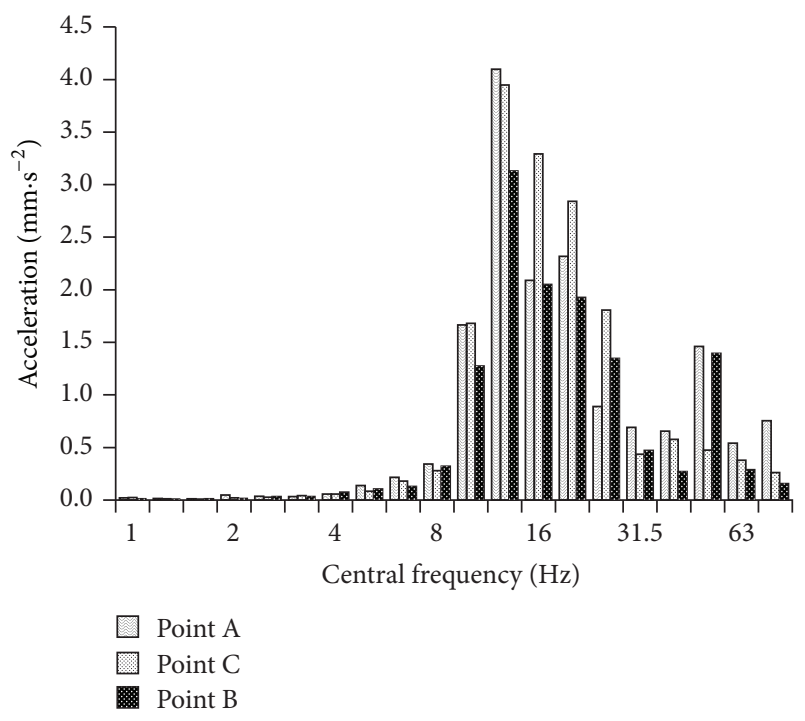

FIGURE 16: The peak acceleration of the central frequency.

A to the prediction point is very short, the phase differences between different frequency signals are neglected.

Figure 17 shows that the measured acceleration is close to the predicted acceleration. Therefore, the proposed prediction method is considered effective and accurate.

5.2. Ground Vibration under Heavy Trunks. To predict the vibration responses of the structure under heavy trunks using the prediction method, the measurement points are arranged along a road, on which the speeds and loads of the vehicles are close to those of the vehicles on the Yanfu east road, but with a greater traffic flow, and the field test is just as shown in Figure 18.

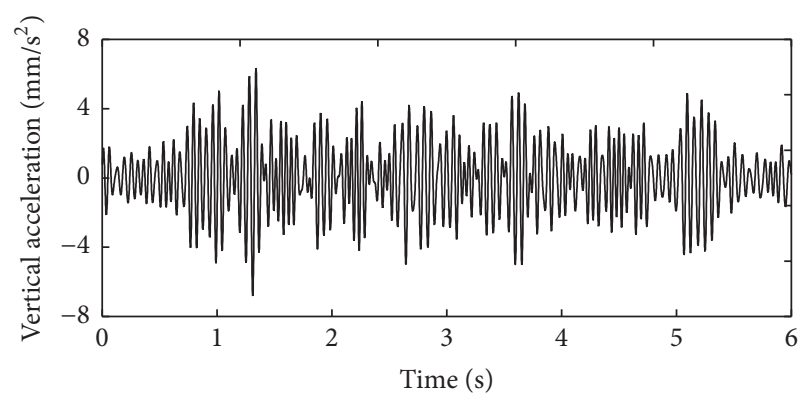

(a) Measured

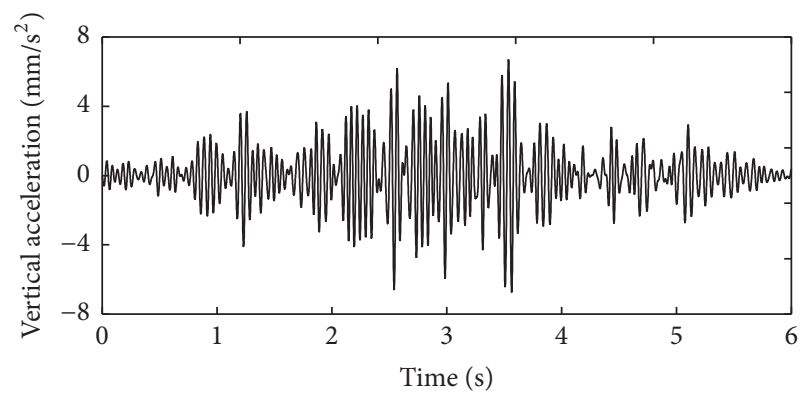

(b) FEM

FIGURE 17: Acceleration time history at the measurement point of the 2 nd floor.

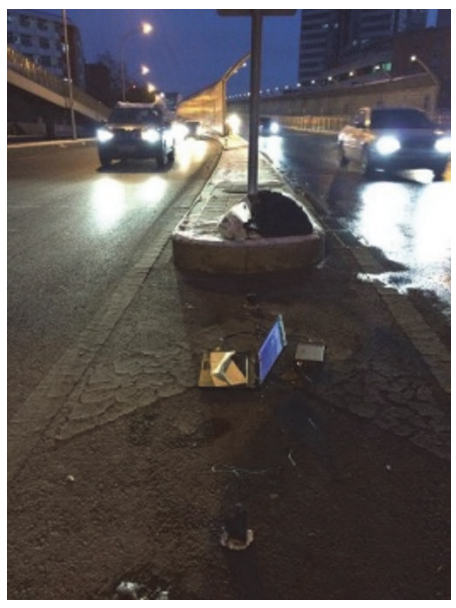

FIGURE 18: Field tested acceleration along a road.

The measured acceleration at the roadside is considered to be the vibration responses of point $\mathrm{A}$, and the vibration responses of point $\mathrm{C}$ induced by each single frequency signal are obtained using the transfer function method proposed in this paper. The measured acceleration in the $Z$-direction along the side of the road is shown in Figure 19.

5.3. Vibration Prediction. The acceleration history of the frequency band $12.5 \mathrm{~Hz}$ calculated using the transfer method is shown in Figure 20.

Then, the structural vibration responses induced by each single frequency signal are superimposed, and the superimposed vibration response of the 2 nd floor is shown in Figure 21. 


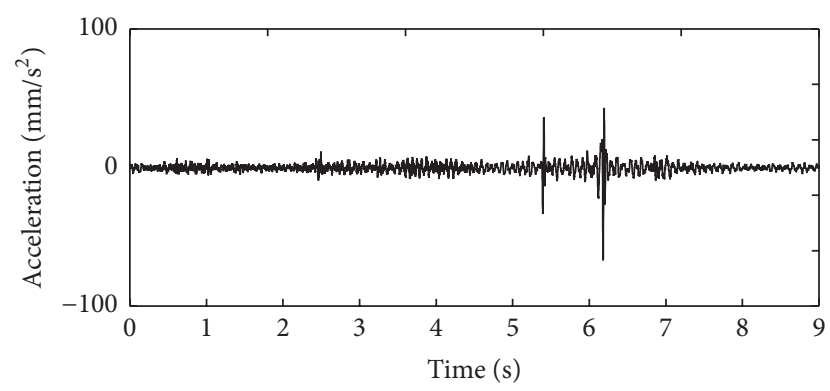

Figure 19: Acceleration time history at point $\mathrm{A}$ in the $\mathrm{Z}$-direction.

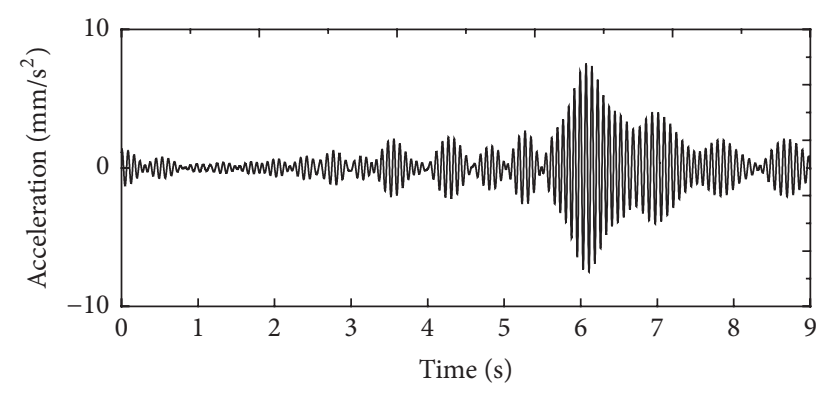

FIgURE 20: Acceleration time histories for $12.5 \mathrm{~Hz}$.

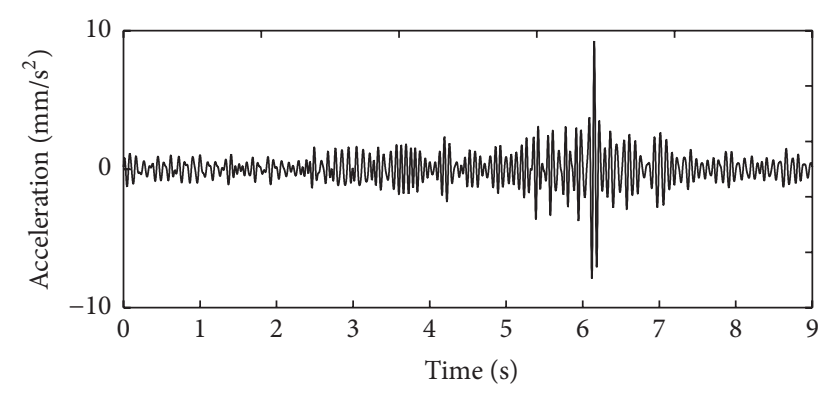

FIgURE 21: Acceleration time history at the prediction point on the 2nd floor.

Comparing Figures 19 and 21 shows that the moment when the peak acceleration appears at point $\mathrm{A}$ and at the prediction point is almost the same. The corresponding peak acceleration is $67 \mathrm{~mm} / \mathrm{s}^{2}$ and $9.3 \mathrm{~mm} / \mathrm{s}^{2}$, respectively; therefore, the effectiveness of this method is verified.

\section{Conclusion}

A vibration prediction method for historical timber buildings induced by traffic loads is proposed and validated by an in situ experiment. The building FE model is updated using the double-confirmation analysis method based on the auto-PSD, the cross-PSD, and the frequency response function of the studied structure. The transfer function can be obtained by analyzing the acceleration time histories of two vibration points. Additionally, the structural vibration responses induced by heavy trunks are predicted using the combination FEM and the transfer function. This prediction method can effectively predict the vibration responses of a building without detailed field tests.

\section{Conflicts of Interest}

The authors declare that they have no conflicts of interest.

\section{Acknowledgments}

This study is supported by the key project of the National Natural Science Foundation (Grant no. 51338001) and the State Fundamental Research Funds "973" Program (Grant no. 2013CB036203) of China.

\section{References}

[1] S. Uçak, A. Bayraktar, T. Türker, and G. Osmancikli, "Finiteelement model calibration of historical masonry domes using operational modal testings," Journal of Performance of Constructed Facilities, vol. 30, no. 2, 2016.

[2] I. Çalik, A. Bayraktar, T. Türker, and H. Karadeniz, "Structural dynamic identification of a damaged and restored masonry vault using ambient vibrations," Measurement, vol. 55, pp. 462472, 2014.

[3] Z. Cagnan, "Numerical models for the seismic assessment of St. Nicholas Cathedral, Cyprus," Soil Dynamics and Earthquake Engineering, vol. 39, pp. 50-60, 2012.

[4] F. Ceroni, S. Sica, M. Rosaria Pecce, and A. Garofano, "Evaluation of the natural vibration frequencies of a historical masonry building accounting for SSI," Soil Dynamics and Earthquake Engineering, vol. 64, pp. 95-101, 2014.

[5] A. Bayraktar, T. Türker, and A. C. Altunişik, "Experimental frequencies and damping ratios for historical masonry arch bridges," Construction and Building Materials, vol. 75, pp. 234241, 2015.

[6] D. Foti, M. Diaferio, N. I. Giannoccaro, and M. Mongelli, "Ambient vibration testing, dynamic identification and model updating of a historic tower," NDT \& E International, vol. 47, pp. 88-95, 2012.

[7] C. Rainieri, G. Fabbrocino, and G. M. Verderame, "Nondestructive characterization and dynamic identification of a modern heritage building for serviceability seismic analyses," NDT and E International, vol. 60, pp. 17-31, 2013.

[8] T. Maeda, Y. Sugiura, and T. Hirai, "FEM modeling of the towers in Bayon temple in Cambodia based on micro-tremor measurements," Advances in Engineering Software, vol. 39, no. 4, pp. 346-355, 2008.

[9] P. Cacciola and A. Tombari, "Vibration control of structures through structure-soil-structure interaction," in Proceedings of the 9th International Conference on Structural Dynamics (Eurodyn '14), pp. 559-566, Leuven; Belgium, September 2014.

[10] M. Breccolotti, A. L. Materazzi, D. Salciarini, C. Tamagnini, and F. Ubertini, "Vibrations induced by the new underground railway line in Palermo, Italy Experimental measurements and FE modeling," in Proceedings of the 8th International Conference on Structural Dynamics (EURODYN '11), pp. 719-726, July 2011.

[11] G. D. Giulio, M. Vassallo, G. Boscato, A. Dal Cin, and S. Russo, "Seismic monitoring by piezoelectric accelerometers of a damaged historical monument in downtown L'Aquila," Annals of Geophysics, vol. 57, no. 6, pp. 654-669, 2014.

[12] B. Sevim, A. Bayraktar, A. C. Altunişik, S. Atamtürktür, and F. Birinci, "Assessment of nonlinear seismic performance of a restored historical arch bridge using ambient vibrations," Nonlinear Dynamics, vol. 63, no. 4, pp. 755-770, 2011. 
[13] A. Bayraktar, F. Birinci, A. C. Altunişik, T. Türker, and B. Sevim, "Finite element model updating of Senyuva historical arch bridge using ambient vibration tests," Baltic Journal of Road and Bridge Engineering, vol. 4, no. 4, pp. 177-185, 2009.

[14] A. G. El-Attar, A. M. Saleh, and A. H. Zaghw, "Conservation of a slender historical Mamluk-style minaret by passive control techniques," Structural Control and Health Monitoring, vol. 12, no. 2, pp. 157-177, 2005.

[15] S. El-Borgi, H. Smaoui, F. Casciati, K. Jerbi, and F. Kanoun, "Seismic evaluation and innovative retrofit of a historical building in Tunisia," Structural Control and Health Monitoring, vol. 12, no. 2, pp. 179-195, 2005.

[16] M. Marchisio, L. Piroddi, G. Ranieri, S. V. Calcina, and P. Farina, "Comparison of natural and artificial forcing to study the dynamic behaviour of bell towers in low wind context by means of ground-based radar interferometry: the case of the Leaning Tower in Pisa," Journal of Geophysics and Engineering, vol. 11, no. 5, 2014.

[17] M. Crispino and M. D’Apuzzo, "Measurement and prediction of traffic-induced vibrations in a heritage building," Journal of Sound and Vibration, vol. 246, no. 2, pp. 319-335, 2001.

[18] A. Schiavi and L. Rossi, "Vibration perception in buildings: a survey. From the historical origins to the present day," Energy Procedia, vol. 78, pp. 2-7, 2015.

[19] D.-Y. Ding, S. Gupta, W.-N. Liu, G. Lombaert, and G. Degrande, "Prediction of vibrations induced by trains on line 8 of Beijing metro," Journal of Zhejiang University SCIENCE A, vol. 11, no. 4, pp. 280-293, 2010.

[20] H. Chebli, R. Othman, and D. Clouteau, "Response of periodic structures due to moving loads," Comptes Rendus-Mecanique, vol. 334, no. 6, pp. 347-352, 2006.

[21] J. L. Yuan, H. Fan, and H. B. Chen, "Experimental study of dynamic behave of Hu Qiu Pagoda," Experimental Study of Dynamic Behave of Hu Qiu Pagoda, vol. 22, no. 5, pp. 158-164, 2005 (Chinese).

[22] M. Ma, V. Markine, W.-N. Liu, Y. Yuan, and F. Zhang, "Metro train-induced vibrations on historic buildings in Chengdu, China," Journal of Zhejiang University: Science A, vol. 12, no. 10, pp. 782-793, 2011.

[23] GB/T 50452-2008, Technical Specifications for Protection of Historic Buildings Against Man-Made Vibration, China Building Industry Press, Beijing, China, 2008 (Chinese). 


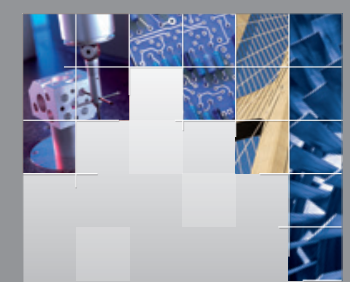

\section{Enfincering}
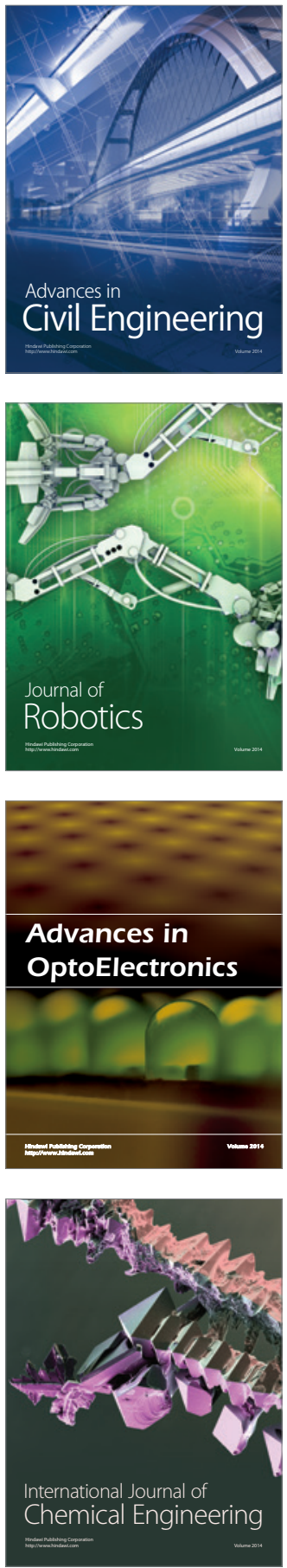

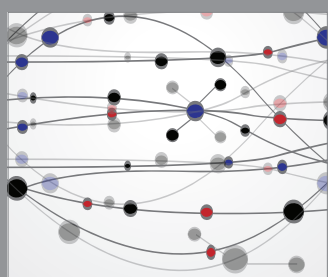

The Scientific World Journal

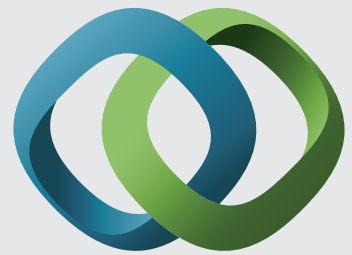

\section{Hindawi}

Submit your manuscripts at

https://www.hindawi.com
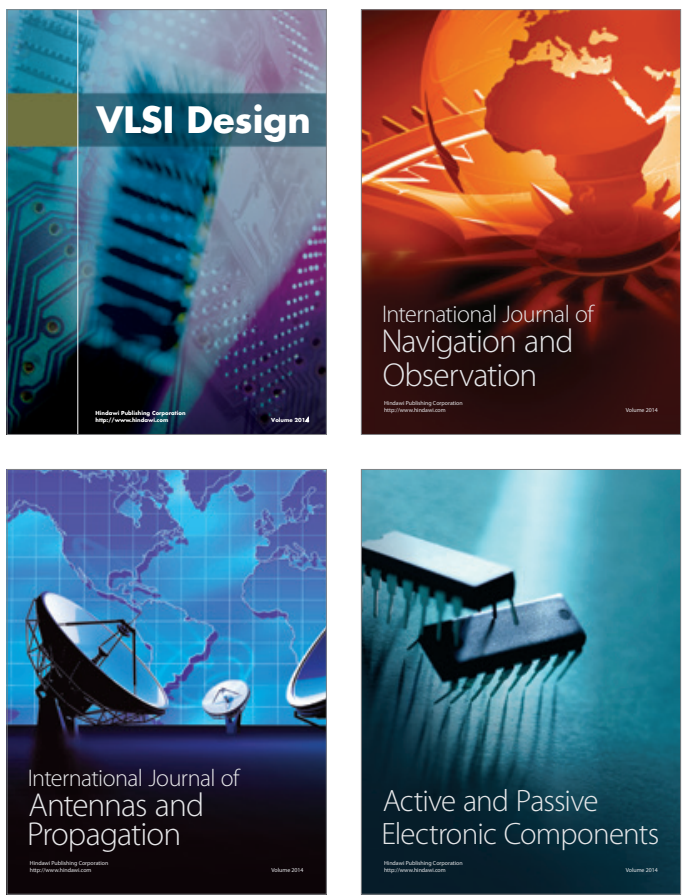
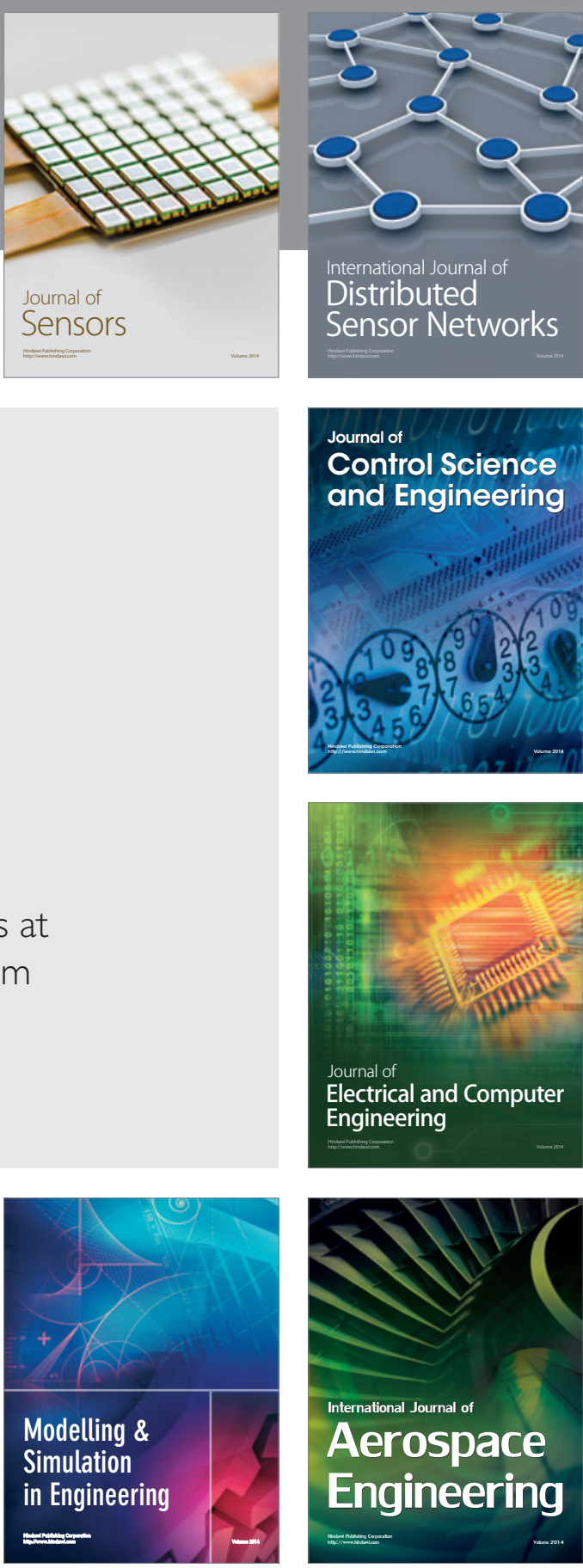

International Journal of

Distributed

Sensor Networks

$-$

Joumal of

Control Science

and Engineering
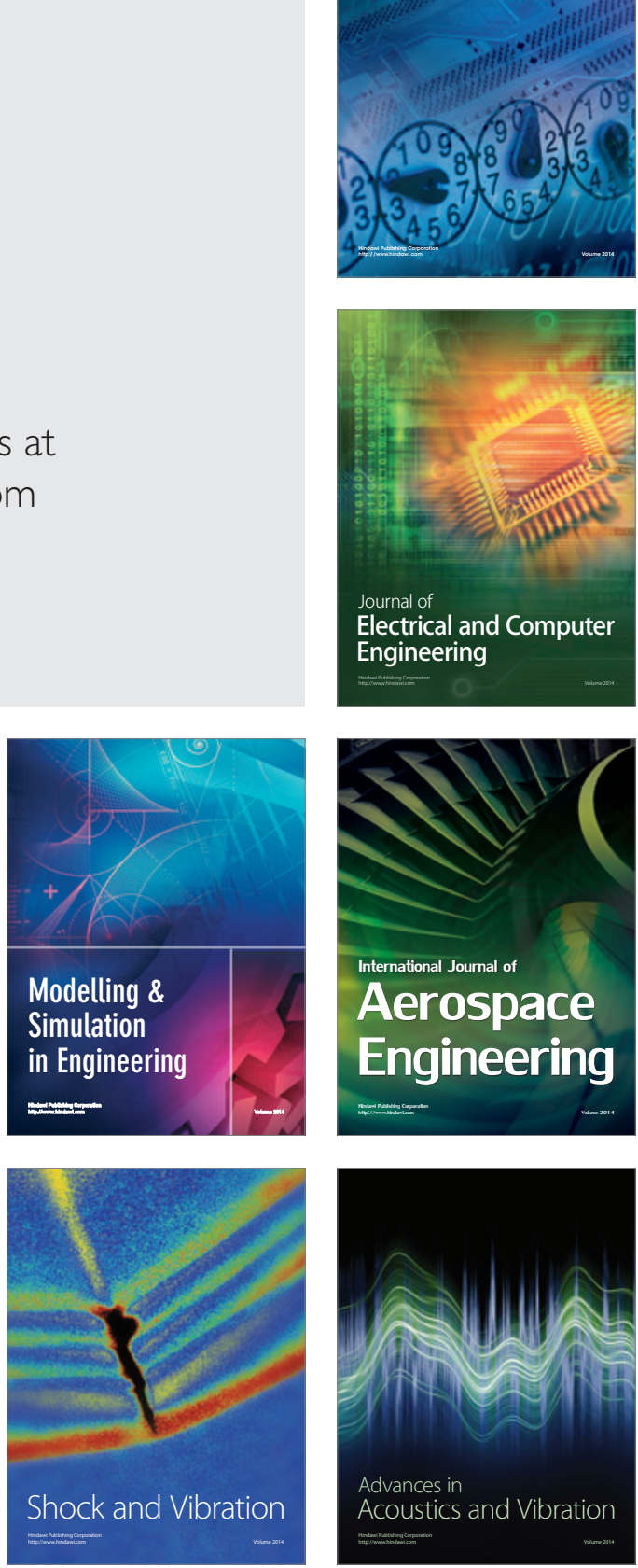